\title{
浮上式流動層 $\mathrm{CVD}$ による $\mathrm{TiN}-\mathrm{Al}_{2} \mathrm{O}_{3}$ 系複合粉末の合成
}

\author{
木村勇雄 - 堀田憲康 - 一 箭健治 - 齋藤夏風 \\ (新潟大学工学部化学工学科, 950-21 新潟市五十嵐 2 の町 8050)
}

\section{Synthesis of TiN- $\mathrm{Al}_{2} \mathrm{O}_{3}$ Composite Powder by Floating-Type Fluidized-Bed CVD}

\author{
Isao KIMURA, Noriyasu HOTTA, Kenji ICHIYA and Natsukaze SAITO \\ (Department of Chemical Engineering, Faculty of Engineering, Niigata University, ) \\ 8050, Ikarashi 2-no-cho, Niigata-shi 950-21
}

\begin{abstract}
$A \mathrm{TiN}-\mathrm{Al}_{2} \mathrm{O}_{3}$ composite powder was synthesized by the floating-type fluidized-bed $\mathrm{CVD} . \mathrm{Al}_{2} \mathrm{O}_{3}$ particles were floated in an $\mathrm{N}_{2} / \mathrm{NH}_{3}$ gas mixture, and $\mathrm{TiCl}_{4}$ was fed to deposit TiN. The composite powders obtained and the ceramics were examined by an electron probe microanalyzer (EPMA). The TiN content in the composite powder was controlled by the flow rate of

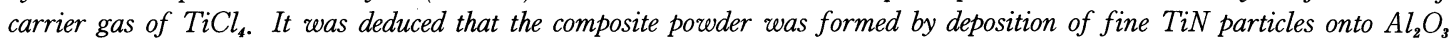
particle surfaces, aggregating to about $3 \mu \mathrm{m}$. Ceramic from the composite powder containing 12.5 wt $\%$ TiN was conductive. Its microstructure suggested that TiN was uniformly dispersed as compared with mechanical mixing.
\end{abstract}

[Received May 8, $1989 ;$ Accepted August 22, 1989]

Key-words : Fluidized-bed $\mathrm{CVD}$, Composite powder, $\mathrm{Al}_{2} \mathrm{O}_{3}, \mathrm{TiN}, \mathrm{TiCl}_{4}, \mathrm{NH}_{3}$, Conductive ceramics, Dispersion

\section{1. 緒 言}

アルミナ $\left(\mathrm{Al}_{2} \mathrm{O}_{3}\right)$ セラミックスは機械的強度が大きく, 化学的にも安定であるが，靶性にそしいので，第二相を 分散させ複合セラミックスとすることにより，それらの

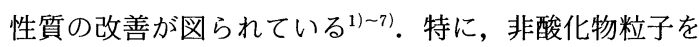
分散させた複合セラミックスは，強度や硬度など他の機 械的性質の向上と共に熱的性質の向上も期待でき $る^{6) \sim 9)}$.

複合粉末を得るための方法としては, ( 1 )機械的混合, （2）２成分系 CVD，（3）流動層 CVD 等が考えられる. （1）では, 非酸化物粉末が一般に高硬度であるため混 合機からの污染が避けられず, 品質低下を招く恐れがあ る.（2）は, 酸化物-酸化物系あるいは非酸化物-非酸 化物系の合成には有効であるが, 酸化物-非酸化物系の 合成には不適当である. 前記二者に比較して, (3) は 一方の成分粉末を流動化させ, 他方の成分を CVD 合成 する方法であるため, 機械的混合を省いて複合粉末が合 成でき, また種々の複合粉末を対象とした組み合わせが 可能である. したがって, この方法は $\mathrm{Al}_{2} \mathrm{O}_{3}$-非酸化物 系複合粉末の合成にも適すると考えられる.

これまでのサブミクロン粒子を用いた流動層 CVD で は, 粒子を流動化させるためには約 $50 \mu \mathrm{m}$ の凝集体を 形成させなければならないので，この凝集体内における CVD の均一性と組成の均一分散性に問題点があった。 著者らは以前, 窒化物微粉末を合成するための浮上式流 動窒化法を報告した ${ }^{10)}$. この手法では, 流動化ガスの流 量を制御することにより浮上する粒子の粒度を制御で
き, 凝集の少ない粉末が得られるので, サブミクロン粒 子の流動層 CVD に応用できるものと考える，そこで， $\mathrm{Al}_{2} \mathrm{O}_{3}$ 微粉末を窒素 $\left(\mathrm{N}_{2}\right)$-アンモニア $\left(\mathrm{NH}_{3}\right)$ 気流中に 浮上させ,ここに四塩化チタン $\left(\mathrm{TiCl}_{4}\right)$ を導入するこ とによって窒化チタン $(\mathrm{TiN})-\mathrm{Al}_{2} \mathrm{O}_{3}$ 系複合粉末を合成 したところ, 良好な結果が得られた。ここでは, 合成条 件と TiN 含有量の関係について述べるとともに, 複合 の形態を電子線マイクロアナライザ (EPMA) による 元素分布の分析亡微細構造の観察及び焼結体の導電性か ら推論する.

\section{2. 実 験}

実験に使用した原料を表 1 に示す. $\mathrm{Al}_{2} \mathrm{O}_{3}$ 粉末の走查 型電子顕微鏡 (SEM) 写真を図 1 に示す. そのメジア ン径は遠心沈降式粒度分布測定装置により $0.63 \mu \mathrm{m}$ と 求められた。

実験装置の概略を図 2 に示す.内径 $35 \mathrm{~mm}$, 長さ $1000 \mathrm{~mm} の \mathrm{Al}_{2} \mathrm{O}_{3}$ 管を反応器に用い, 垂直に設置した. $\mathrm{Al}_{2} \mathrm{O}_{3}$ 粉末は靦拌回転子上に落下させ，ここに導入した $\mathrm{N}_{2}-\mathrm{NH}_{3}$ 混合ガスをキャリアとして反応器内に浮上, 輸

Table 1. Raw materials used in the experiments.

\begin{tabular}{lll}
\hline Raw material & Purity / & Manufacturer \\
\hline $\mathrm{Al}_{2} \mathrm{O}_{3}$ & 99.5 & Showa Electric Ind. \\
$\mathrm{TiCl}_{4}$ & reagent grade & Junsei Chemical \\
$\mathrm{N}_{2}$ & 99.9995 & Teisan \\
$\mathrm{NH}_{3}$ & 99.9995 & Showa Electric Ind. \\
\hline
\end{tabular}




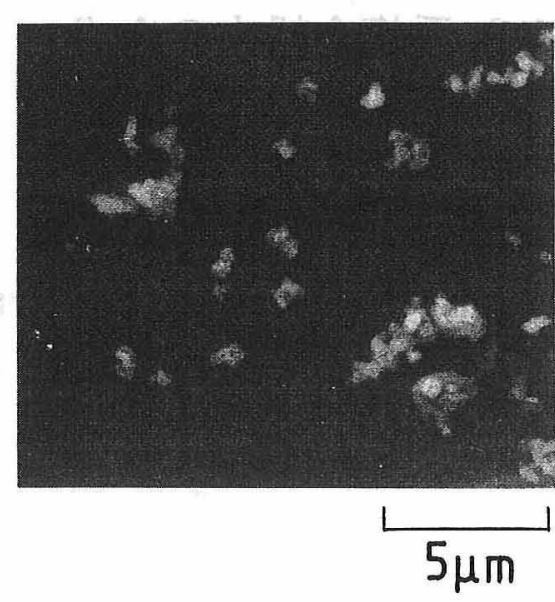

Fig. 1. $\mathrm{Al}_{2} \mathrm{O}_{3}$ powder as a raw material.

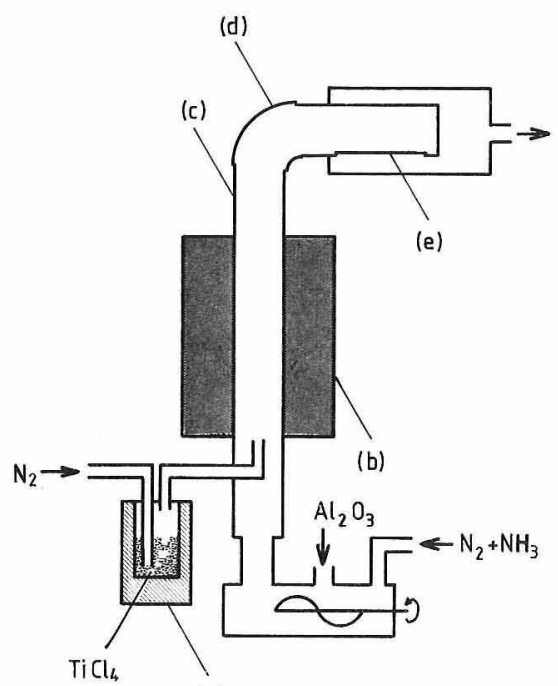

(a)

Fig. 2. Schematic illustration of the reactor assembly.

(a) Mantle heater, (b) Electric furnace,

(c) Reactor (Alumina tube), (d) Silicone tube,

(e) Filter paper.

送した。 $\mathrm{TiCl}_{4}$ はマントルヒーター（a）で $150^{\circ} \mathrm{C} に$ 加 熱して蒸発させ， $\mathrm{N}_{2}$ をキャリアとして反応器中心から $310 \mathrm{~mm}$ 下方の位置に導入した。この導入口の温度は $290^{\circ} \mathrm{C}$ であった. $\mathrm{Al}_{2} \mathrm{O}_{3}$ 粉末浮上用 $\mathrm{N}_{2}$ ガス (以下, $\mathrm{Al}_{2} \mathrm{O}_{3}$ 用 $\mathrm{N}_{2}$ と記す) の流量は $1400 \sim 1600 \mathrm{~cm}^{3} \cdot \mathrm{min}^{-1}$, $\mathrm{NH}_{3}$ 流量は $200 \sim 400 \mathrm{~cm}^{3} \cdot \mathrm{min}^{-1}, \mathrm{TiCl}_{4}$ 供給用 $\mathrm{N}_{2}$ ガス (以下, $\mathrm{TiCl}_{4}$ 用 $\mathrm{N}_{2}$ と記す) の流量は $50 \sim 300 \mathrm{~cm}^{3}$. $\mathrm{min}^{-1}$ とした. 反応器中心部温度は以下のようにして决 定した. $1200^{\circ}, 1300^{\circ}, 1450^{\circ}, 1500^{\circ}, 1550^{\circ} \mathrm{C}$ の各温度 において $\mathrm{Al}_{2} \mathrm{O}_{3}$ 粉末を浮上させずに同様の操作を行い, 得られた TiN 粉末の遠心沈降径を測定した．その結果， 合成温度が高いほどメジアン径は小さくなることがわ
かったので, より高い焼結性が期待できる粉末が得られ る合成温度として $1550^{\circ} \mathrm{C}$ を選んだ. 生成した複合粉末 は沪紙 (e) で捕集した後, $\mathrm{N}_{2}$ 気流中, $500^{\circ} \mathrm{C}, 3 \mathrm{~h}$ 加熱 することにより副生成物の塩化アンモニウム $\left(\mathrm{NH}_{4} \mathrm{Cl}\right)$ を除去した。

精製後の粉末については，X線回折により相の同定と ケイ素 $(\mathrm{Si})$ を内部標準とする格子定数の測定を行った. $\mathrm{TiN}$ 中の $\mathrm{N}$ の含有量は大気雾囲気中にて $1000^{\circ} \mathrm{C}, 30$ $\min$ 加熱したときの酸化重量増加から求めた。 TiN の 含有量は $\mathrm{Al}_{2} \mathrm{O}_{3}(113)$ と $\mathrm{TiN}(200)$ の X 線回折強度を 比較することにより，あらかじめ作製しておいた検量線 を基に算出した。粉末粒子の形状と $\mathrm{Al}$ 及び $\mathrm{Ti}$ の分布 はEPMAによって分析した。焼結は圧力 $280 \mathrm{MPa} の$ 下で $\phi 8 \times 4 \mathrm{~mm}$ の円盤状に成形した後， $\mathrm{N}_{2}$ 雾囲気中， 圧力 $30 \mathrm{MPa}$ の下で $1700^{\circ} \mathrm{C}, 1 \mathrm{~h}$ ホットプレスすること により行った．粉末成形体及び焼結体の体積抵抗率は, 真鍮製円盤を試料雨面に圧着して電極とし，デジタルマ ルチメーターにより測定した。

\section{3. 結果と考察}

$\mathrm{TiCl}_{4}$ を供給せずに $\mathrm{Al}_{2} \mathrm{O}_{3}$ 粉末のみを浮上させた後の 粒度を測定したところ,その遠心沈降メジアン径は $3.05 \mu \mathrm{m}$ となった. この結果によって, 通常の流動層に 比べて凝集の少ない, より微細な粒子を流動化できるこ とが磼認できた。実際に $\mathrm{TiCl}_{4}$ を供給して TiN を析出 させた場合にも，粒度はほとんど同じであった。

得られた複合粉末のX線回折図からはいずれの合成条 件に拈いても， $\mathrm{Al}_{2} \mathrm{O}_{3}$ と立方晶 $\mathrm{TiN}$ の回折線のみが検 出された。 TiN の格子定数は $0.4239 \mathrm{~nm}$ と求められた (文献値 $0.4240 \mathrm{~nm}^{11)}$ ). この值と加藤らの結果 ${ }^{12)}$ を比 較し, 酸化に上る重量増加を合わせて考えると, 本研究 で得られた TiN の N/Ti 比は 1.10 となり, 化学量論組 成の TiN よりも幾分公素過剩型であることが分かった.

$\mathrm{Al}_{2} \mathrm{O}_{3}$ と $\mathrm{TiN}$ の回折強度は $\mathrm{TiCl}_{4}$ 用 $\mathrm{N}_{2}$ の流量によっ て変化した。これは両成分の複合比が変化したためと予 測された。 そこで, 回折強度から $\mathrm{TiN}$ 含有量を求めた ところ, 図 3 に示す結果を得た. 図 3 は $\mathrm{Al}_{2} \mathrm{O}_{3}$ 浮上用の $\mathrm{N}_{2}-\mathrm{NH}_{3}$ 混合ガス総流量を $1800 \mathrm{~cm}^{3} \cdot \mathrm{min}^{-1}$ とした場合 の, $\mathrm{TiCl}_{4}$ 用 $\mathrm{N}_{2}$ の流量と得られた複合粉末中の $\mathrm{TiN}$ 含 有量との関係である.このように $\mathrm{TiN}$ 含有量は $\mathrm{TiCl}_{4}$ 用 $\mathrm{N}_{2}$ の流量を増加させることにより増加した。 すなわ ち, $\mathrm{Al}_{2} \mathrm{O}_{3}$ と TiN の複合比はほぼ全組成の範囲にわた り，簡便な操作で制御できることが分かった。

図 4 は TiN をそれぞれ $12.5 \mathrm{wt} \%$ (a)，52 wt\% (b) 及び $76 \mathrm{wt} \%$ (c) 含む複合粉末二二次電子線像及び $\mathrm{Al}$ とTi の X線像である.

$\mathrm{TiN}$ 含有量 $12.5 \mathrm{wt} \%$ の場合, 粒子表面上に $0.2 \mu \mathrm{m}$ 以下の微細な粒子が観察されるがここが TiNである 


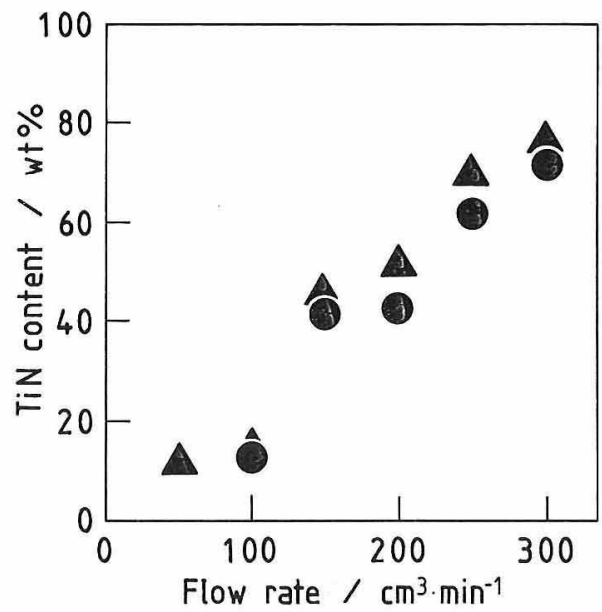

Fig. 3. Relation between TiN content in the composite powder and a flow rate of carrier gas of $\mathrm{TiCl}_{4}$. $\Delta$ : Flow rate of $\mathrm{N}_{2}$ for $\mathrm{Al}_{2} \mathrm{O}_{3}$ is $1600 \mathrm{~cm}^{3} \cdot \mathrm{min}^{-1}$ and of $\mathrm{NH}_{3}$ is $200 \mathrm{~cm}^{3} \cdot \mathrm{min}^{-1}$, Flow rate of $\mathrm{N}_{2}$ for $\mathrm{Al}_{2} \mathrm{O}_{3}$ is $1400 \mathrm{~cm}^{3} \cdot \mathrm{min}^{-1}$ and of $\mathrm{NH}_{3} 400 \mathrm{~cm}^{3} \cdot \mathrm{min}^{-1}$.
かどうかは判断できなかった。また，X線像では，Ti の分布は一様であるように見えるが，TiN の分布が連 続的であったとも断定できなかった．なぜなら，TiN が $\mathrm{Al}_{2} \mathrm{O}_{3}$ 粒子の表側に存在しなくても，裏側に付着して

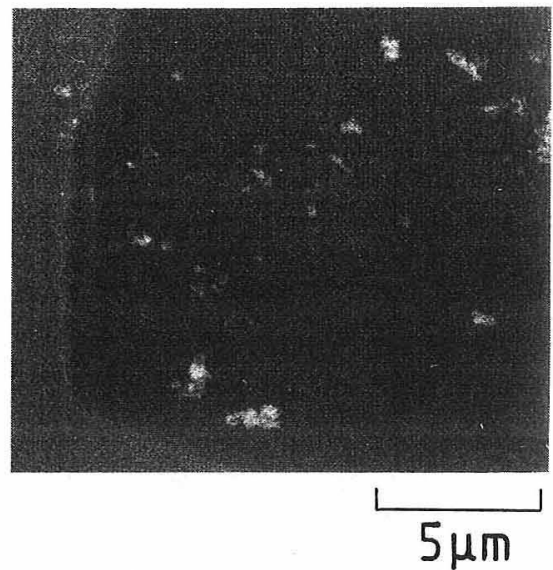

Fig. 5. TiN powder prepared by $\mathrm{CVD}$ at $1550^{\circ} \mathrm{C}$.
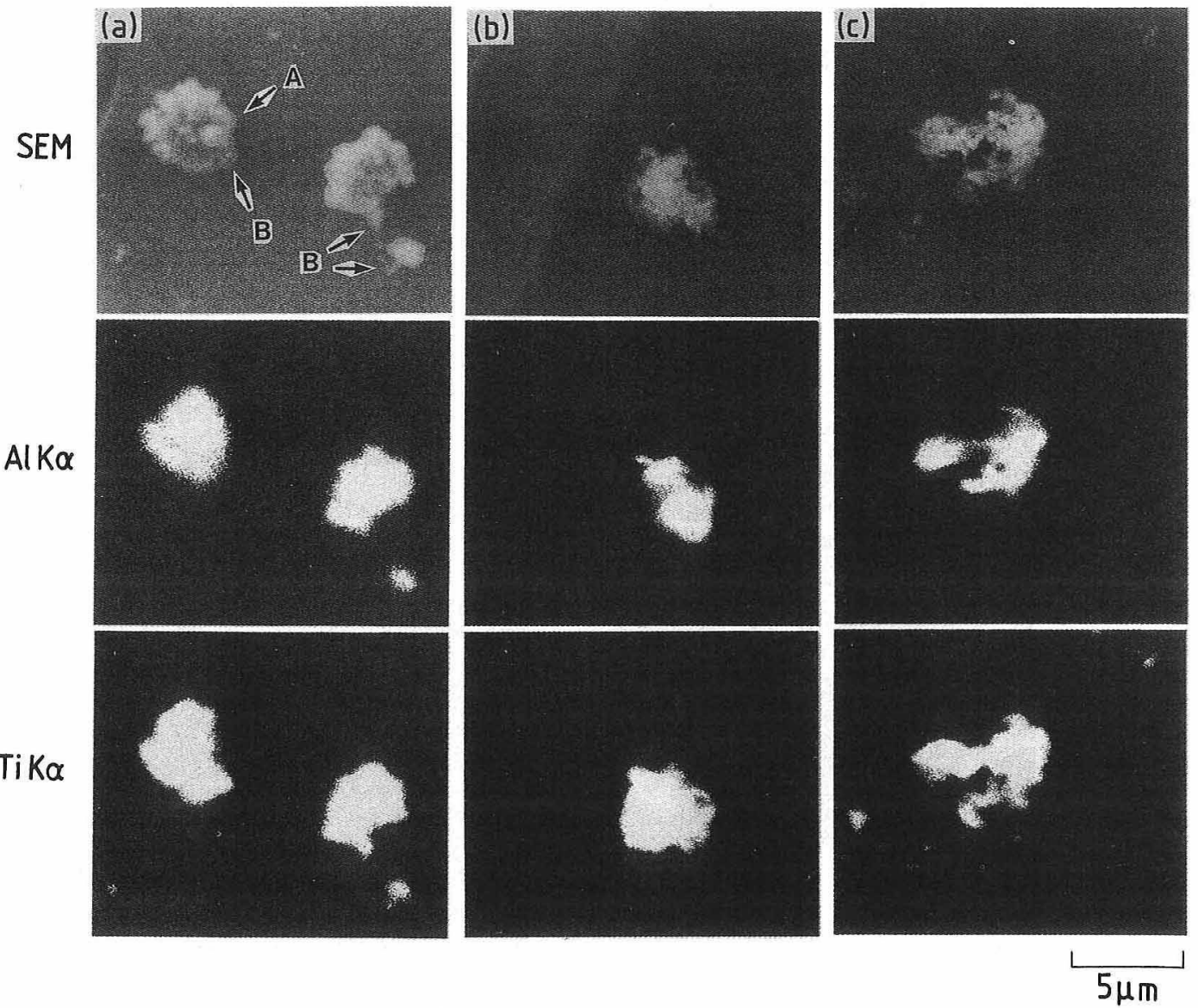

Fig. 4. Electron probe microanalysis of the composite powders.

(a) $12.5 \mathrm{wt} \% \mathrm{TiN}$, (b) $52 \mathrm{wt} \% \mathrm{TiN}$, (c) $76 \mathrm{wt} \% \mathrm{TiN}$. Arrow A designates an area, on which TiN was not deposited. Arrows B designate fine TiN particles deposited on the $\mathrm{Al}_{2} \mathrm{O}_{3}$ particle. 
いた場合には Ti が検出されるからである．ただし，矢 印 $\mathrm{A} て ゙$ 示した部分では $\mathrm{Ti}$ は検出されないので，少なく ともこの部分には TiN は存在しておらず, TiN は $\mathrm{Al}_{2} \mathrm{O}_{3}$ 粒子を完全に被覆していないことは明らかであ る. また，矢印 Bで示した突起状の部分では Al は検出 されず，Ti のみが検出されたので，この部分は TiNで ある。これらはその形状から微粒子状 TiN であると考 えられ, 気相中での均一核生成によって生成した TiN 微粒子が $\mathrm{Al}_{2} \mathrm{O}_{3}$ 粒子表面に沈積したものと推測される.
TiN 含有量が増すと $\mathrm{Al}$ に比べて Ti が検出される面 積が大きくなり， TiN 粒子が $\mathrm{Al}_{2} \mathrm{O}_{3}$ 粒子に厚く堆積す る様子が観察される．TiN 含有量 $76 \mathrm{wt} \%$ の複合粉末で は，複合粒子から分離した TiN のみからなる $0.2 \mu \mathrm{m}$ 以下の粒子が観察された。これは，気相中の TiN 濃度 が高いために, $\mathrm{Al}_{2} \mathrm{O}_{3}$ 粒子に付着する前に $\mathrm{TiN}$ 微粒子 間での凝集が起こって生じたものと思われる.

次に, 本研究で合成した複合粉末から焼結体を作製し， 機械的に混合した粉末から作製した焼結体と微細構造を
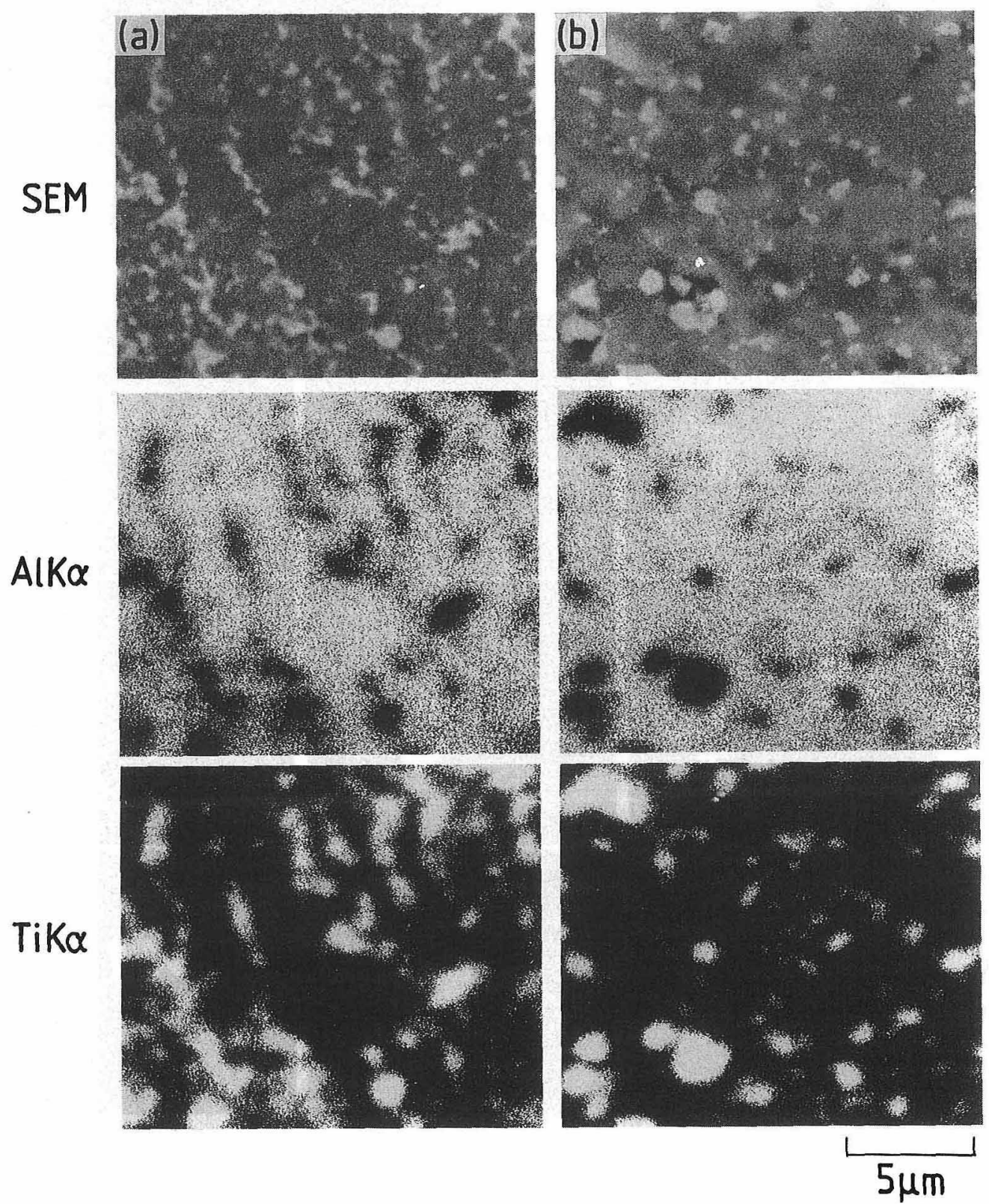

Fig.6. Electron probe microanalysis of the ceramics containing $12.5 \mathrm{wt} \%$ TiN.

(a) Prepared from the composite powder, (b) Prepared from the mechanically mixed powder. 
Table 2. Properties of $\mathrm{TiN}-\mathrm{Al}_{2} \mathrm{O}_{3}$ composites.

\begin{tabular}{lcc}
\hline & Density $/ \mathrm{g} \cdot \mathrm{cm}^{-3}$ & Resistivity $/ \Omega \cdot \mathrm{cm}$ \\
\hline (1) Composite, As-pressed & 2.08 & $>10^{9}$ \\
(2) Mixed, As-pressed & 2.18 & $>10^{9}$ \\
(3) Composite, Sintered & 4.15 & $7.5 \times 10^{-1}$ \\
(4) Mixed, Sintered & 4.05 & $>10^{9}$ \\
\hline
\end{tabular}

比較することにより，TiN の分散性を検討した．TiN$\mathrm{Al}_{2} \mathrm{O}_{3}$ 系複合粉末成形体及びその複合セラミックスの密 度と体積抵抗率を測定した結果を表 2 に示す。（1）は 図 4(a) に示した複合粉末を成形したものである.（2） は $\mathrm{Al}_{2} \mathrm{O}_{3}$ 粉末に $\mathrm{TiN}$ 微粉末を（1）と同じ組成になる ように配合し,エタノールを分散媒として乳鉢で混合し， 成形したものである.ここで用いた TiN 微粉末は，（1） と同じ条件下で $\mathrm{Al}_{2} \mathrm{O}_{3}$ を浮上させずに CVD 合成したも のである.その形状は図 5 に示すようにほぼ球状であり, 遠心沈降メジアン径は $0.38 \mu \mathrm{m}$ であった（ 3 ), ( 4 ) はそれぞれ（1)，（2）の焼結体である.

成形体は（1)，（2）共に抵抗が大きく，導電性を示 さなかった．これは先にも述べたように，この組成では $\mathrm{TiN}$ が $\mathrm{Al}_{2} \mathrm{O}_{3}$ 粒子を完全に被覆していないため, TiN 粒子間の接触が少ないからであると考えられる.

これらをホットプレスすると, 混合粉末から作製した 焼結体（4）は絶縁体のままであったが, 複合粉末から 作製した焼結体（3）は導電性を示すようになった。図 6 にこれらの焼結体の研磨面の EPMA 分析の結果を示 す. 二次電子線像で白く見える領域は TiN であり, そ の周囲の灰色の部分は $\mathrm{Al}_{2} \mathrm{O}_{3}$ である.

複合粉末から作製した焼結体（a）中の TiN 粒子は, その多くが $0.5 \mu \mathrm{m}$ 以下の微細なものである. TiN 粒子 間の連結は平面的には断続的であるように見えるが，焼
結体全体として導電性を示すことから, 三次元的に連結 しているものと考えられる.これに対して, 混合粉末か らの焼結体（b) には $1 \sim 3 \mu \mathrm{m}$ に成長した $\mathrm{TiN}$ 粒子が 観察され, しかも, それらの間の連結はほとんに゙認めら れない。この場合, TiN 含有量が $12.5 \mathrm{wt} \%$ (9.5 vol\%) と少ないので, 粉末中の TiN は凝集せずに均一に分散 しなければ焼結後の連続的な接触は起こらない。した がって,このような微細構造の差は, 流動層 CVD によ る分散の均一性が機械的混合によるよりも高いことを示 唆するものと考えられる.

謝辞 EPMAによる分析に関して多くのご便宜を頂いた 新潟大学歯学部・小林正義氏に厚く感謝致します. ホットプレ スと粒度分布の測定に関しては装置の使用許可と数々のご協力 を賜りました新潟県工業技術センター複合材料科・高橋眞一科 長とそのグループの皆様に謝意を表します. 本研究の一部は, 文部省科学研究費 (No. 01750862) の援助のもとに行われました.

\section{文 献}

1) N. Claussen, J. Am. Ceram. Soc., 59, 49-51 (1976).

2) N. Claussen, J. Steeb and R.F. Pabst, Am. Ceram. Soc. Bull., 56, 559-62 (1977).

3) D. J. Green, J. Am. Ceram. Soc., 65, 610-14 (1982).

4) K. Tsukuma, K. Ueda and M. Shimada, J. Am. Ceram. Soc., 68, C4-5 (1985).

5) S. R. Witek and E. P. Butler, ibid., 69, 523-29 (1986).

6) R. P. Wahi and B. Ilschner, J. Mater. Sci., 15, 875-85 (1980).

7) 中平 敦, 新原晧一, 平井敏雄, 窯協, 94, 767-72 (1986).

8) M. Lee and M.P. Borom, Adv. Ceram. Mater., 3, 38-44 (1988).

9) I. Kimura, N. Hotta, Y. Hiraoka, N. Saito and Y. Yokota, J. Eur. Ceram. Soc., 5, 23-27 (1989).

10）堀田憲康, 木村勇雄, 一箭健治, 齊藤夏風, 安川三郎, 多田清志, 北村照夫, セラミックス論文誌, 96, 731-35 (1988).

11) ASTM Powder Diffraction File (INORGANIC), 6-0642.

12）加藤昭夫, 岩田正歳, 北條純一, 永野正光, 窯協, 83, 453-59 (1975). 